\title{
Adrenal 21-hydroxylase gene mutations in Slovenian hyperandrogenic women: evaluation of corticotrophin stimulation and HLA polymorphisms in screening for carrier status
}

\author{
Vita Dolžan ${ }^{1}$, Janez Preželj ${ }^{2}$, Blanka Vidan-Jeras ${ }^{3}$ and Katja Breskvar ${ }^{1}$ \\ ${ }^{1}$ Institute of Biochemistry, Faculty of Medicine, Ljubljana, Slovenia, ${ }^{2}$ Department of Endocrinology and Metabolism, University Medical Centre, \\ Ljubljana, Slovenia and ${ }^{3}$ Tissue Typing Centre, Blood Transfusion Centre of Slovenia, Ljubljana, Slovenia \\ (Correspondence should be addressed to V Dolžan, Institute of Biochemistry, Faculty of Medicine, Vrazov trg 2, 1000 Ljubljana, Slovenia; Email: \\ dolzan@ibmi.mf.uni-lj.si)
}

\begin{abstract}
Objective: To study the incidence of 21-hydroxylase deficiency in Slovenian hyperandrogenic women, at the gene level. Previous endocrine studies indicated large differences in the incidence of 21-hydroxylase deficiency in hyperandrogenic women. The predictive values of the 17-hydroxyprogesterone (17-OHP) response to ACTH stimulation and of HLA typing in screening for carrier status were re-evaluated. Design: Molecular analysis of CYP21 gene, ACTH stimulation and human leucocyte antigen (HLA) typing were performed in 83 consecutive Slovenian hyperandrogenic women.

Measurements: Cortisol and 17-OHP concentrations were measured at baseline and $60 \mathrm{~min}$ after ACTH stimulation. Basal adrenal androgen concentrations were also measured.

Results: None of 83 hyperandrogenic patients was affected with non-classical 21-hydroxylase deficiency, but 12 of 81 patients $(14.8 \%)$ had high concentrations of $17-\mathrm{OHP}$ after stimulation, indicative of carrier status. The increase in 17-OHP concentrations could be explained by a carrier status for CYP21 gene mutations in only three of 12 patients $(25 \%)$, whereas seven of 69 patients (10.1\%) with normal concentrations of 17-OHP after stimulation were found to be carriers of CYP21 gene mutations, indicating low positive predictive values of ACTH stimulation as a screening test for carriers of 21-hydroxylase deficiency. In total, 11 carriers were identified among 83 patients: seven CYP21 gene deletions/conversions, two $\mathrm{Gln}^{318}$ Stop and one $\mathrm{Val}^{281}$ Leu mutation and one gene conversion extending from exon 4 to exon 7 were found. The association between $\mathrm{Val}^{281} \mathrm{Leu}$ mutation and HLA-B14 antigen was confirmed in this Slovenian population.

Conclusions: Basal or ACTH-stimulated 17-OHP concentrations are not a good indicator of the carrier status for 21-hydroxylase deficiency among Slovenian hyperandrogenic patients. Reliable screening for carriers of 21-hydroxylase deficiency is possible only by molecular analysis of the CYP21 gene.
\end{abstract}

European Journal of Endocrinology 141 132-139

\section{Introduction}

Non-tumoral hyperandrogenism is one of the most common endocrinological disorders in women. It is manifested by one or more of the following clinical signs and symptoms: oligo/amenorrhoea, decreased fertility, hirsutism, acne resistant to treatment or androgenic alopecia. Increased plasma concentrations of one or more adrenal or ovarian androgens are often found (1). There is no specific marker on the basis of which hyperandrogenism could be distinguished from the polycystic ovary syndrome (PCOS), especially as polycystic ovaries are also detected by ultrasound in healthy women without clinical signs of hyperandrogenism (2). Heterogeneity of clinical symptoms and biochemical features in hyperandrogenism complicates the search for its possible genetic causes (3). Mutations in the 21 -hydroxylase gene, the $11 \beta$-hydroxylase gene, the $3 \beta$-hydroxysteroid dehydrogenase gene and the insulin receptor gene have been found to be associated with hyperandrogenism (4).

Non-classical congenital adrenal hyperplasia (NC$\mathrm{CAH}$ ) caused by 21-hydroxylase deficiency is one of the most common genetic defects. Its incidence is $1 / 1000$ in white populations, in general but is much higher in some selected populations: $1 / 27$ in Askhenazi Jews, 1/53 in Spaniards, 1/63 in Croats and 1/330 in Italians $(5,6)$. The incidence of $\mathrm{NC}-\mathrm{CAH}$ in hyperandrogenic women has been reported to be $1.2-20 \%$ (7-9). This variability may be due to a different frequency of $\mathrm{NC}-\mathrm{CAH}$ in studied populations of different ethnic origin or differences in selection criteria, but may also reflect 
difficulty in distinguishing between NC-CAH and nontumoral hyperandrogenism on the basis only of clinical symptoms and hormonal findings. The corticotrophin (ACTH) test is used to identify NC-CAH, but it is difficult to distinguish between the conditions when the 17hydroxyprogesterone (17-OHP) response to ACTH stimulation is above normal $(9.6 \mathrm{nmol} / \mathrm{l})$ but below values characteristic of NC-CAH $(36 \mathrm{nmol} / \mathrm{l})(7)$. It has been suggested that hyperandrogenic women with borderline increases in 17-OHP after ACTH stimulation are heterozygous carriers of mutations in the 21hydroxylase gene (CYP21) (10). In agreement with this, it was reported that 55 of 69 French hyperandrogenic women carried mutations in the CYP21 gene (11). It has also been suggested that heterozygosity for 21-hydroxylase deficiency may be associated with adolescent hyperandrogenism (12). In contrast, it seems that obligate heterozygous carriers of CYP21 gene mutations are not at increased risk for hyperandrogenism (13).

CYP21 genes located in the central region of the major histocompatibility complex (MHC) on chromosome 6 are in close genetic linkage with human leucocyte antigens (HLA) (14). Characteristic HLA haplotypes are associated with $\mathrm{CAH}$, but this association differs among populations. In some populations, up to $70 \%$ of $\mathrm{NC}-\mathrm{CAH}$ alleles are characterised by $\mathrm{Val}^{281}$ Leu mutation of CYP21 genes and are associated with ancestral haplotype 65.1 characterised by HLA-B14, -C4A2, -C4B1+2, -DR1 (5, $15)$; however, these markers seem to be absent from Croatian patients with NC-CAH (6). In populations with known associations between HLA haplotypes and disease, HLA typing can help to identify carriers.

The aims of our study were: to determine the incidence of NC-CAH in Slovenian hyperandrogenic women, to find out if HLA associations with $\mathrm{CAH}$ described in the literature are also valid for the Slovenian population and could be used for screening purposes, and to define if the carrier status for CYP21 gene mutations is reflected in the basal plasma androgen concentrations or in the 17-OHP response to ACTH stimulation, or both.

\section{Study participants and methods}

\section{Study participants}

The study population consisted of 83 Slovenian female hyperandrogenic patients, aged 17-32 years (median 24 years), referred to the outpatient endocrinological unit in Ljubljana. They were complaining of one or more of the following clinical symptoms: oligo/amenorrhoea (12 of the patients were oligomenorrhoeic, the others eumenorrhoeic), hirsutism, acne resistant to treatment, or androgenic alopecia. The presence of hirsutism was assessed by the examining endocrinologist, but was not formally scored. The presence of polycystic ovaries as determined by ultrasound was not a selection criterion. Androgensecreting tumours and thyroid dysfunction were excluded by clinical and hormonal findings.

Family members of patients who had CYP21 gene mutations or increased 17-OHP after an ACTH test were asked to participate in the study. Eleven family members of four patients agreed to take part in HLA typing and molecular analysis, but were not hormonally tested.

Two control groups were analysed for point mutations in the CYP21 gene. The first control group of 18 young women aged 20-29 years (median 21 years) served also to provide information on the normal basal and stimulated 17-OHP and cortisol concentrations in the healthy Slovenian population. All were eumenorrhoeic, without clinically evident signs of hirsutism or acne, and none was receiving hormonal medication. The second control group consisted of 38 DNA samples randomly chosen from Slovenian female blood donors previously typed for HLA (16).

The study design was approved by the Slovene Ethical Committee for Research in Medicine. Written informed consent was obtained from all participants in the study.

\section{ACTH testing and hormonal analysis}

The ACTH test was performed with $0.25 \mathrm{mg}$ ACTH i.m. (Synacthen; Ciba-Geigy, Basel, Switzerland) between 0800 and $0900 \mathrm{~h}$. Healthy controls and eumenorrhoeic hyperandrogenic women were tested in the early follicular phase. Blood samples were obtained at $0 \mathrm{~min}$ and $60 \mathrm{~min}$ after the administration of ACTH and were assayed for 17OHP and cortisol. Normal upper basal and stimulated concentrations of 17-OHP were determined as mean+ 2s.D. of those in healthy controls and were less than $4.1 \mathrm{nmol} / \mathrm{l}$ for basal $17-\mathrm{OHP}$ and less than $9.8 \mathrm{nmol} / \mathrm{l}$ for stimulated 17-OHP. In patients, basal blood samples were also assayed for free testosterone (normal value $<7.7 \mathrm{pmol} / \mathrm{l}$ ), androstenedione (normal value $<11.6 \mathrm{nmol} / \mathrm{l}$ ) and dehydroepiandrosterone sulphate (DHEAS; normal value $<8.8 \mathrm{mmol} / \mathrm{l}$ ). The following RIA kits were used: free testosterone, Diagnostic Products Corporation (DPC; Los Angeles, CA, USA); androstenedione, Immunotech International (Marseille, France); DHEAS, Diagnostic System Laboratories (Webster, TX, USA); 17-OHP, DPC. A fluoroimmunoassay kit from Wallac (Turku, Finland) was used to determine cortisol concentration. The mean intra- and interassay coefficients of variation (CV) were less than $6 \%$.

\section{HLA typing}

Standard microlymphocytotoxicity testing (17) was used to determine class I HLA phenotypes in 77 female hyperandrogenic patients. A local set of serostatistically defined polyclonal alloantisera and polyclonal alloantisera from Biotest (Dreieich, Germany) were used. HLA-DRB1 alleles were analysed by oligonucleotide hybridisation of PCR-amplified second exons of the HLA-DRB1 gene (18) or by sequence-specific PCR 
Table 1 Primers used for direct sequencing of the CYP21 gene.

\begin{tabular}{|c|c|c|}
\hline Exon & Forward primer* & Reverse primer* \\
\hline $\begin{array}{l}1 \\
2 \\
4+5 \\
6 \\
7 \\
8 \\
9 \\
10\end{array}$ & $\begin{array}{l}\text { (-42) 5'-GAGCTATAAGTGGCACCTCAG-3' } \\
\text { (255) 5'-AGAGGGTCCTCTCTCCGCT-3' } \\
\text { (899) 5'-GCCTGCTGAACTCACACTG-3' } \\
\text { (1282) 5'-CTCCTTCCCACAGCTGCATT-3' } \\
\text { (1511) 5'-GCCTGTTGCCACTCTGTACTC-3' } \\
\text { (2000) 5'-CACTGGGTTGCTGAGGGAG-3' } \\
\text { (2172) 5'-TTGGGGATGAGTGAGGAAAG-3' } \\
\text { (2384) 5'-TGCCGTGAAAATGTGGTGGA-3' }\end{array}$ & 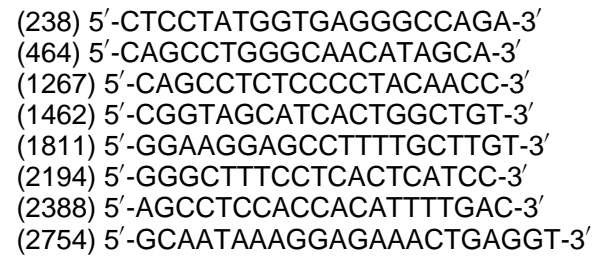 \\
\hline
\end{tabular}

* Primers were designed using the Primer3 program by S Rozen \& HJ Skaletsky, 1996 available at http:/wwwgenome.wi.mit.edu/genome_software/other/primer3.html

(Dynal; Oslo, Norway) (19). The data obtained from the group of 38 healthy controls previously typed for HLA alleles (16) were used to compare HLA frequencies.

\section{Molecular analysis}

DNA was isolated from peripheral blood leucocytes (20). Ten micrograms genomic DNA were digested with TaqI restriction endonuclease. Fragments were separated on $0.7 \%$ agarose gels and blotted on the Hybond $\mathrm{N}^{+}$ membrane (21). Two cDNA probes, CYP21 probe (22) and $\mathrm{C} 4$ probe $(23)$, were labelled with ${ }^{32} \mathrm{P}$-dCTP and used to determine CYP21 and C4 gene deletions, duplications and large gene conversions in 64 hyperandrogenic patients. Both probes were obtained through the courtesy of M C Carroll (Harvard University, Boston, MA, USA). Because only TaqI digests were analysed, gene conversions involving the TaqI restriction site were not distinguishable from deletions of the CYP21 gene. Deletions/conversions of CYP21 were identified by decreased intensity of the $3.7 \mathrm{~kb}$ TaqI fragment compared with that of the $3.2 \mathrm{~kb}$ TaqI fragment (24).

To screen for point mutations, exons $1-3$ and exons 3-8 of the CYP21 gene were selectively amplified with two sets of primers (25) in all patients and controls. Dot blot hybridisation analysis of the PCR product with 3'DIG-ddUTP end-labelled oligonucleotides was used to screen for the presence of normal or mutated sequences at the following eight sites of the CYP21 gene: Pro ${ }^{30} \mathrm{Leu}$ (exon 1), A/ $\mathrm{C}^{656} \mathrm{G}$ (-13 intron 2), $\mathrm{Ile}^{172}$ Asn (exon 4), Ile-Val-Glu-Met ${ }^{236-239}$ Asn-Glu-Glu-Lys (exon 6), $\mathrm{Val}^{281} \mathrm{Leu}$ (exon 7), insT $\mathrm{T}^{307}$ (exon 7), Gln ${ }^{318}$ Stop (exon 8) and Arg $^{356}$ Trp (exon 8). Oligonucleotide sequences were essentially as previously described (25). Allele-specific PCR was used to analyse for an 8 bp deletion in exon 3 (26).

For sequence analysis, the CYP21 gene and its proximal promoter region were first specifically amplified in two large fragments, the first extending from -264 in the proximal promoter region to the CYP21-specific site in exon $3(986 \mathrm{bp}$, forward primer 5'-AGCTGACTCTGGATGCAGGA-3', reverse primer
5'-AGCAGGGAGTAGTCTCCCAAG $-3^{\prime}$ ) and the second comprising exons 3 to $10\left(2095 \mathrm{bp}\right.$, forward primer $5^{\prime}$ TTGTCCTTGGGAGACTACTCC-3', reverse primer $5^{\prime}$ ACTGTGTTTACAGGGGGGAG-3'). Amplified fragments were purified on QIAquick PCR purification columns (Quiagen, Hilden, Germany) and sequenced by $\alpha-{ }^{35}$ SdATP incorporation with the forward and reverse primers shown in Table 1, using an AmpliCycle sequencing kit (Perkin Elmer, Roche Molecular Systems, Branchburg, NJ, USA).

\section{Statistical analysis}

Hormonal data are expressed as means \pm s.D. Student's $t$-test was used for statistical analysis of hormonal data. $\chi^{2}$ and Fisher's exact test were used to compare HLA phenotype frequencies between patients and controls. Statistical significance was assigned a value of $P<0.05$.

\section{Results}

\section{7-OHP responses to ACTH stimulation}

The individual values of basal and stimulated 17-OHP concentrations in Slovenian hyperandrogenic patients are shown in Fig. 1. All patients were subjected to an ACTH test, but 17-OHP was determined only in 81 patients, among whom $20(24.7 \%)$ demonstrated basal $17-\mathrm{OHP}$ values greater than $4.1 \mathrm{nmol} / \mathrm{l}$. At $60 \mathrm{~min}$, increased 17-OHP concentrations (range 9.8$21.5 \mathrm{nmol} / \mathrm{l})$ were found in 12 of 81 patients $(14.8 \%)$. No patient demonstrated stimulated 17-OHP greater than $36.6 \mathrm{nmol} / \mathrm{l}$ that would be consistent with 21 hydroxylase deficient NC-CAH (7). Basal 17-OHP concentrations were significantly greater in hyperandrogenic women than in healthy controls $(3.3 \pm 2.0$ compared with $2.5 \pm 0.8 \mathrm{nmol} / \mathrm{l} ; P=0.006)$. However, stimulated 17-OHP concentrations were similar in both groups (7.0 \pm 3.1 compared with $6.6 \pm 2.0 \mathrm{nmol} / \mathrm{l})$. Basal cortisol $(397 \pm 152 \mathrm{nmol} / \mathrm{l}$ and $396 \pm 116 \mathrm{nmol} / \mathrm{l})$ and stimulated cortisol concentrations $(727 \pm 147 \mathrm{nmol} / \mathrm{l}$ and $716 \pm 72 \mathrm{nmol} / \mathrm{l}$ ) were not significantly different between the groups. 


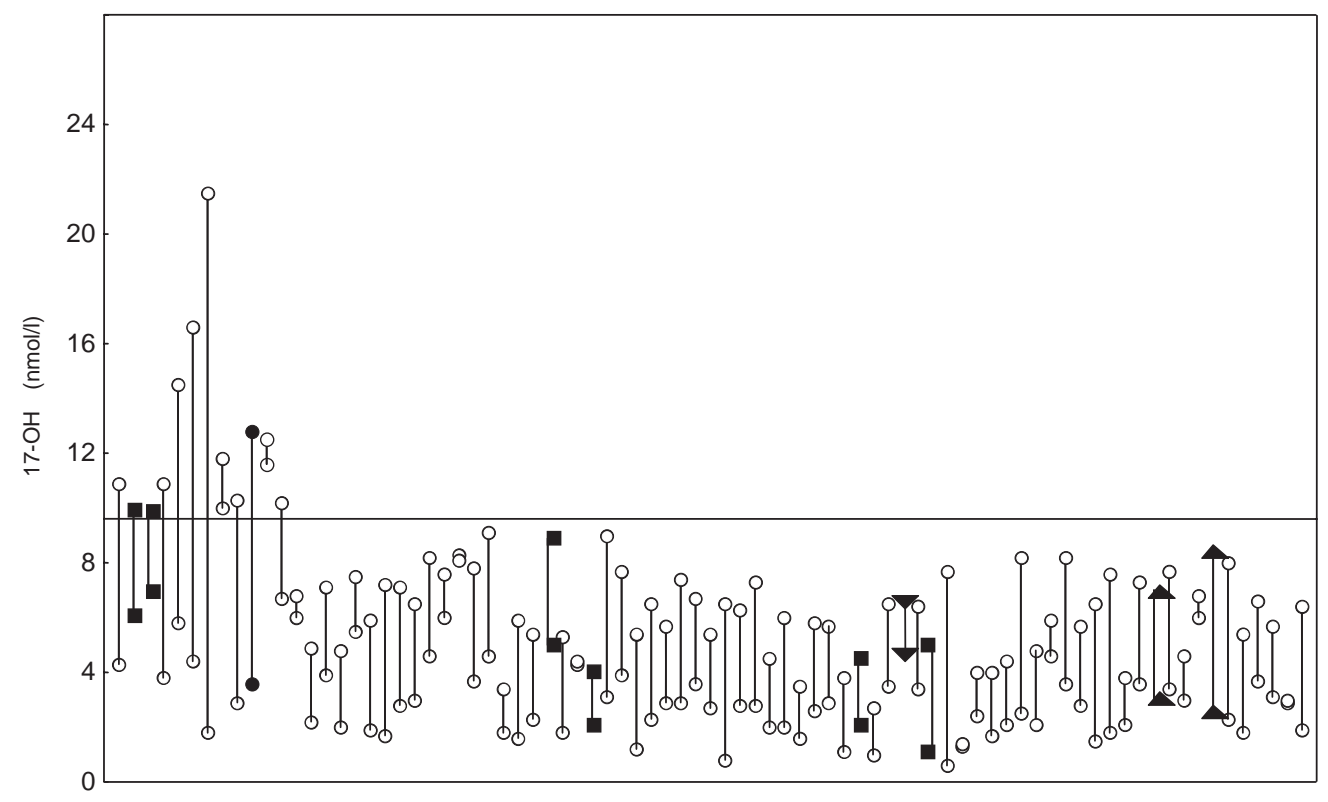

Figure $117-\mathrm{OHP}$ concentrations before and $60 \mathrm{~min}$ after ACTH stimulation in Slovenian female hyperandrogenic patients. $\mathrm{O}$, no mutations

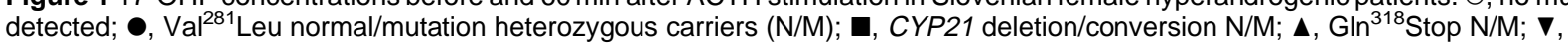
conversion in exon 4 to exon 7 region N/M. Horizontal line represents the mean+2s.D. of stimulated 17-OHP values in the control group.

\section{CYP21 gene mutations and HLA associations}

Eleven heterozygous carriers of CYP21 mutations were identified among 83 hyperandrogenic patients analysed (13.3\%). Basal and stimulated 17-OHP concentrations, HLA haplotypes and specificity of mutations in hyperandrogenic carriers of CYP21 gene mutations are shown in Table 2.

CYP21 gene deletion/conversion carriers were identified among seven of 64 hyperandrogenic patients (10.9\%), of whom two had high and four had normal stimulated 17-OHP values. In one patient, 17-OHP was not determined. CYP21 gene deletions/conversions were not associated with HLA-B47 typical for CAH in Northern European populations. HLA-B40, but not HLA-DR1, was present in two patients with CYP21 gene deletion/conversion.

Three heterozygous carriers of CYP21 point mutations and one gene conversion encompassing four exons were identified among 83 hyperandrogenic patients $(4.8 \%)$. Point mutations identified were $\mathrm{Val}^{281} \mathrm{Leu}$ in one and $\mathrm{Glu}^{318}$ Stop in two patients. Similar to the findings described by Weddel et al. (27), in one patient, four consecutive mutations were found $-\mathrm{Ile}^{172} \mathrm{Asn}$,

Table 2 17-OHP concentrations at baseline and $60 \mathrm{~min}$ after ACTH stimulation, and HLA haplotypes, in female hyperandrogenic carriers of CYP21 gene mutations.

\begin{tabular}{|c|c|c|c|c|}
\hline \multirow[b]{2}{*}{ Patient } & \multicolumn{2}{|c|}{ 17-OHP (nmol/l) } & \multirow[b]{2}{*}{ HLA haplotype } & \multirow{2}{*}{$\begin{array}{c}\text { CYP21 } \\
\text { mutations }\end{array}$} \\
\hline & $0 \mathrm{~min}$ & $60 \mathrm{~min}$ & & \\
\hline E36 & 6.1 & 9.9 & A28 A24 B62 BX DR1 DR13 & conv/del N/M \\
\hline E46 & 6.8 & 9.6 & A3 A24 B18 B40 DR11 DR13 & conv/del N/M \\
\hline E2 & 1.3 & 5.0 & A28 A3 B51 B44 DR16 DR7 & conv/del N/M \\
\hline E12 & 5.0 & 8.9 & A24 A26 B51 B56 DR3 DR11 & conv/del N/M \\
\hline E21 & ND & ND & A2 A11 B38 B35 DR1 DR16 & conv/del N/M \\
\hline E33 & 1.9 & 4.1 & A2 A24 B21 B40 DR11 DR14 & conv/del N/M \\
\hline E89 & 2.1 & 3.8 & A3 A34 B44 B35 DR7 DR14 & conv/del N/M \\
\hline E83 & 3.6 & 12.8 & A3 A32 B14 BX DR13 DR13 & ${ }^{281} \mathrm{~N} / \mathrm{M}$ \\
\hline E54 & 5.0 & 6.5 & A3 A26 B51 B35 DR4 DR8 & conv Ex4-7 N/M \\
\hline E77 & 2.5 & 8.4 & A1 A2 B8 B50 DR3 DR7 & ${ }^{318} \mathrm{~N} / \mathrm{M}$ \\
\hline E72 & 2.9 & 7.0 & A2 A23 B62 B50 DR1 DR3 & ${ }^{318} \mathrm{~N} / \mathrm{M}$ \\
\hline
\end{tabular}

$\mathrm{ND}$, not done; conv, conversion; del, deletion; N/M, heterozygous carrier; Ex. exon.

Polymorphisms and neutral mutations are not shown. 
A Family E77

I

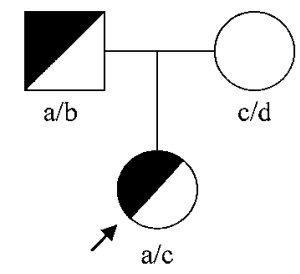

$\begin{array}{ll}\text { a } & \text { A2 B50 DR7 } \\ \text { b } & \text { A1 B37 DRX } \\ \text { c } & \text { A1 B8 DR3 } \\ \text { d } & \text { A2 B44 DR4 }\end{array}$

B Family E2

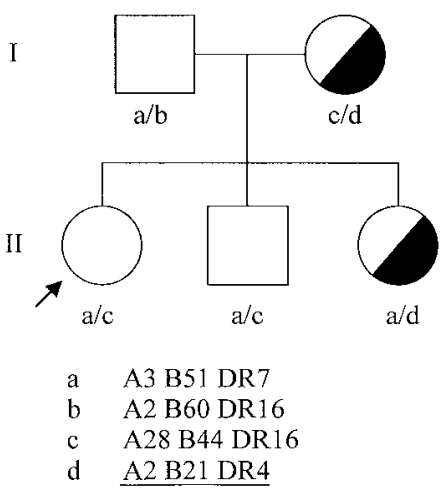

Figure 2 Pedigrees of two families affected by the $\mathrm{Gln}{ }^{318}$ Stop mutation. a, b, c, d, HLA haplotypes of family members; haplotypes associated with mutation are underlined. Open symbols represent ${ }^{318} \mathrm{GIn}$; half-solid symbols represent heterozygous carriers of the Gln ${ }^{318}$ Stop mutation. Arrows indicate female hyperandrogenic patients.

cluster of mutations in exon 6, $\mathrm{Val}^{281} \mathrm{Leu}$ and insertion of $\mathrm{T}^{307}$ - and a gene conversion extending from exon 4 to exon 7 was suspected, because of the normal response to ACTH stimulation. The carriers of $\mathrm{Glu}^{318-}$ Stop mutation, a mutation frequently found in patients with classical 21-hydroxylase deficiency, had normal $17-\mathrm{OHP}$ values after stimulation. $\mathrm{Gln}^{318}$ Stop mutation was associated with HLA-A2 and -B50 in both patients; in one, this association was confirmed by a family study (Fig. 2A).

The carrier of the $\mathrm{Val}^{281} \mathrm{Leu}$ mutation on the HLAB14 DR13 extended haplotype showed an elevated 17$\mathrm{OHP}$ response to ACTH stimulation. To investigate further the association between HLA-B14 and $\mathrm{Val}^{281} \mathrm{Leu}$ mutation in the Slovenian population, five additional DNA samples of HLA-B14 carriers were selected from the registry of the Tissue Typing Centre in Ljubljana and analysed for point mutations in the CYP21 gene. Three of them $(60 \%)$ were found to be heterozygous carriers of the $\mathrm{Val}^{281}$ Leu mutation (Table 3).

No CYP21 point mutations were found in 56 healthy
Table 3 HLA phenotypes of healthy Slovenian HLA-B14 carriers analysed for $\mathrm{Val}^{281}$ Leu mutation.

\begin{tabular}{lcl}
\hline Carrier & Val $^{\mathbf{2 8 1}}$ Leu & \multicolumn{1}{c}{ HLA phenotype } \\
\hline CTT1 & N/M & A3 A33 B14 B7 DR1 DR13 \\
CTT2 & $N$ & A1 A2 B14 B44 DR7 DR16 \\
CTT3 & $N$ & A1 A33 B14 B7 DR10 DR8 \\
CTT4 & N/M & A28 A33 B14 B18 DR16 DRX \\
CTT5 & N/M & A11 A33 B14 B49 DR3 DR11 \\
\hline
\end{tabular}

$\overline{\mathrm{Val}^{281} \text { Leu, codon 281; N, normal; M, mutation; N/M, heterozygous }}$ carrier.

controls. However, a heterozygous Gln ${ }^{318}$ Stop mutation associated with the HLA-A2 B21 DR4 haplotype (Fig. 2B) was found in the mother and the sister of one hyperandrogenic patient without this mutation.

All mutations detected by oligonucleotide hybridisation were confirmed by sequencing. In addition, sequence analysis of the proximal promoter region, exons and exon-intron junctions of the CYP21 gene was used to screen those hyperandrogenic patients who had high 17-OHP values after stimulation for other mutations or polymorphisms that could explain their exaggerated response to the ACTH test. Sequencing analysis revealed 10 neutral polymorphic sites (mostly in exons 1,7 and 10) in 11 patients, but no additional mutations were found. In the carrier of a gene conversion extending from exon 4 to exon 7 , polymorphisms characteristic of the pseudogene were also present in a heterozygous form.

\section{Adrenal function and serum androgen concentrations in hyperandrogenic carriers of CYP21 gene mutations}

In 27 of 82 hyperandrogenic patients (33\%), one androgen (mostly free testosterone or DHEAS) was increased in serum, and in 20 of the 82 patients (24\%), two androgens were increased. Androstenedione was increased only in two of the $82(2.4 \%)$. To evaluate the influence of CYP21 gene mutations on adrenal function, 17-OHP, cortisol and adrenal androgen concentrations were compared between hyperandrogenic carriers of CYP21 gene mutations and patients without mutations (Table 4). Basal cortisol concentrations were significantly lower in mutation carriers. Concentrations of free testosterone were significantly greater in mutation carriers and the difference in androstenedione concentrations reached borderline statistical significance $(0.1>P>0.05)$. No significant differences in basal or ACTH-stimulated 17-OHP concentrations or in 17-OHP increments were observed between the groups.

\section{Discussion}

The present study represents the first systematic screening for 21-hydroxylase deficiency in Slovenian 
Table 4 17-OHP, cortisol and androgen concentrations in Slovenian female hyperandrogenic patients with and without CYP21 gene mutations. Values are expressed as mean \pm S.D.

\begin{tabular}{lccr}
\hline & $\begin{array}{c}\text { Carriers of CYP21 } \\
\text { mutations }\end{array}$ & $\begin{array}{c}\text { Patients without } \\
\text { CYP21 mutations }\end{array}$ & $\boldsymbol{P}$ \\
\hline 17-OHP $_{0}(\mathrm{nmol} / \mathrm{l})$ & $3.7 \pm 1.9$ & $3.2 \pm 2.0$ & 0.473 \\
17-OHP $_{60}(\mathrm{nmol} / \mathrm{l})$ & $7.6 \pm 2.8$ & $7.0 \pm 3.1$ & 0.540 \\
17-OHP $_{\text {increment }}(\mathrm{nmol} / \mathrm{l})$ & $3.9 \pm 2.3$ & $3.8 \pm 2.9$ & 0.874 \\
Cortisol $(\mathrm{nmol} / \mathrm{l})$ & $308 \pm 57$ & $409 \pm 157$ & 0.048 \\
Free testosterone $(\mathrm{pmol} / \mathrm{l})$ & $11.5 \pm 9.4$ & $7.9 \pm 4.0$ & 0.035 \\
Androstenedione $(\mathrm{nmol} / \mathrm{l})$ & $8.0 \pm 3.6$ & $5.9 \pm 2.9$ & 0.059 \\
DHEAS (mmol/l) & $10.1 \pm 4.1$ & $8.1 \pm 3.8$ & 0.119 \\
\hline
\end{tabular}

17- $\mathrm{OHP}_{0}, 17-\mathrm{OHP}_{60}, 17-\mathrm{OHP}_{\text {increment }}$, concentrations at baseline and 60 min after stimulation with $\mathrm{ACTH}$, and the difference between these values.

hyperandrogenic women. ACTH stimulation, HLA typing and molecular analysis of the CYP21 gene region were used to define the carrier status for 21 hydroxylase deficiency.

High 17-OHP concentrations after stimulation, indicative of heterozygous carriers of 21-hydroxylase deficiency (10), were found in 12 of 81 hyperandrogenic patients $(14.8 \%)$. As no patient demonstrated a stimulated 17-OHP concentration indicative of nonclassical 21-hydroxylase deficiency, we cannot draw any conclusions as to the incidence of non-classical 21hydroxylase deficiency in Slovenian hyperandrogenic women; it may be lower than or consistent with the reported $1-2 \%$ frequency in white hyperandrogenic women in general $(7,8)$. However, high frequencies of non-classical 21-hydroxylase deficiency that are found in some other selected populations (5) are practically excluded in the Slovenian population. Therefore routine screening for 21-hydroxylase deficiency is not recommended in Slovenian hyperandrogenic women.

Molecular analysis of the CYP21 gene revealed that 11 of 83 hyperandrogenic patients $(13.3 \%)$ were heterozygous carriers of 21-hydroxylase deficiency. These results differ from those of Azziz \& Owerbach (10), who found carriers of inherited defects in CYP21 in the majority of patients with an exaggerated 17-OHP response to ACTH stimulation. No point mutations were identified in 56 healthy Slovenian controls.

Carriers of CYP21 gene mutations could not be distinguished from other hyperandrogenic patients on the basis of their response to ACTH stimulation; in fact, the increase in 17-OHP concentrations after ACTH stimulation could be explained by a carrier state for CYP21 gene mutations only in three of 12 patients analysed (25\%). In addition, CYP21 gene mutations were found in 7 of 69 hyperandrogenic patients $(10.1 \%)$ with normal 17-OHP values after stimulation. The response to the ACTH test was normal also in the carrier of a gene conversion extending from exon 4 to exon 7 . Our results indicate that 7 of 11 carriers $(72.7 \%)$ would be missed if ACTH stimulation alone was used as a screening test, and that carriers of severe mutations characteristic of classical 21-hydroxylase deficiency alleles (five of seven deletions/conversions, two of two $\mathrm{Gln}^{318}$ Stop mutations) would be at risk of being given inadequate genetic advice. CYP21 gene mutations that contributed to increased 17-OHP concentrations after ACTH stimulation were two gene deletions/conversions and one $\mathrm{Val}^{281} \mathrm{Leu}$ mutation. The $\mathrm{Val}^{281}$ Leu mutation resulting in an enzyme with decreased activity (28) seems to compromise the adrenal function of the carrier to a greater extent than does the complete absence of the product of one allele.

Our study confirmed the association between $\mathrm{Val}^{281}$ Leu mutation and HLA-B14, a marker characteristic of NC-CAH in several populations $(15,29)$ also in the Slovenian population. Further studies of HLA haplotypes in Slovenian patients with $\mathrm{CAH}$ and their families are needed to ascertain associations between HLA haplotypes and CYP21 gene mutations before HLA typing can be used to screen for carriers.

Heterozygous carriers of CYP21 mutations had higher concentrations of serum free testosterone, androstenedione and DHEAS than patients without CYP21 gene defects. However, the two groups did not differ in basal or ACTH-stimulated 17-OHP concentrations. This is in agreement with observations that heterozigosity for CYP21 mutations may result in mild abnormalities of androgen biosynthesis reflected by higher mean free testosterone $(13,30)$ or by higher mean DHEAS concentrations (10). Our results suggest that, in contrast with findings in patients with NC-CAH, among hyperandrogenic women, basal or ACTHstimulated 17-OHP concentrations are not a good indicator of the carrier status for inherited defects of CYP21, as observed also by other investigators $(13,31$, 32) who defined the carrier status by molecular analysis of CYP21 gene, the most accurate method to define carriers for inherited defects of CYP21 (10). Older studies reported that the majority of heterozygotes for 21-hydroxylase deficiency can be detected by measuring the 17-OHP concentration $60 \mathrm{~min}$ after ACTH stimulation; however, the diagnosis of 21-hydroxylase deficiency was based on HLA genotyping (33). Perhaps 
measuring 21-deoxycortisol (34) and the ratio of 17 OHP/21-deoxycortisol (35), not done in our study, might improve prediction of heterozygous carriers of 21-hydroxylase deficiency by hormonal testing.

It remains unclear what was the cause of borderline elevations in ACTH-stimulated 17-OHP concentrations in nine of 12 hyperandrogenic patients $(75 \%)$, in whom even extensive sequencing of the CYP21 gene and its proximal promoter region revealed no mutations. Falsely positive ACTH tests may be due to high 17OHP concentrations reflecting adrenal and non-adrenal secretion of this steroid precursor (30). Also, other adrenal and ovarian androgens may interfere with adrenal steroidogenesis, mimicking steroid profiles of patients with 21-hydroxylase deficiency (36). Finally, high 17-OHP concentrations may be the consequence of generalised hyperreactivity of the adrenal cortex in hyperandrogenic women (30). Factors other than a mild impairment of 21-hydroxylase activity may also contribute to biochemical findings in these patients (29). Studies of the $17 \alpha$-hydroxylase/17-20-lyase gene showed that mutations in this gene do not contribute to increased stimulated 17-OHP concentrations in Slovenian hyperandrogenic women (37). Further studies may show which additional factors influence the phenotypic traits of 21-hydroxylase deficiency in heterozygous carriers.

In conclusion, our results demonstrate the difficulty in choosing appropriate cut-offs in biochemical tests and the low sensitivity of ACTH stimulation for detection of carriers of 21-hydroxylase deficiency. Reliable detection of carriers is possible only by molecular analysis of the CYP21 gene.

\section{Acknowledgements}

A part of this work was performed during the 12th International Histocompatibility Workshop (12th IHW). We gratefully acknowledge Professor Mariaclara Cuccia, University of Pavia, chairman of the 12th IHW component 'Mutations of CYP21 gene (MHC class III) in pathologies other than $\mathrm{CAH}$, for helpful discussions. This work was financially supported by the Ministry of Science and Technology of Slovenia.

\section{References}

1 Knochenhauer ES, Key TJ, Kahsar-Miller M, Waggoner W, Boots LR \& Azziz R. Prevalence of the polycystic ovary syndrome in unselected black and white women of the southeastern United States: a prospective study. Journal of Clinical Endocrinology and Metabolism 199883 3078-3082.

2 Polson DW, Adams J, Wadsworth J \& Franks S. Polycystic ovaries: a common finding in normal women. Lancet $19881870-872$.

3 Legro RS. The genetics of polycystic ovary syndrome. American Journal of Medicine 199598 (Suppl 1A) 9S-16S.

4 Barbieri RL. Hyperandrogenism: new insights into etiology, diagnosis, and therapy. Current Opinion in Obstetrics and Gynecology $19924372-379$.
5 Speiser PW, Dupont B, Rubinstein P, Piazza A \& New MI. High frequency of nonclassical steriod 21 hydroxylase deficiency. American Journal of Human Genetics 198537 650-667.

6 Dumic M, Brkljacic L, Speiser PW, Wood E, Crawford C, Plavsic V, Banicevic M, Radmanovic S, Radica A, Kastelan A \& New MI. An update on the frequency of nonclassic deficiency of adrenal 21hydroxylase in the Yougoslav population. Acta Endocrinologica $1990122703-710$.

7 Azziz R \& Zacur A. 21-Hydroxylase deficiency in female hyperandrogenism: screening and diagnosis. Journal of Clinical Endocrinology and Metabolism 198969 577-584.

8 Chetkowsky RJ, Defazio J, Shamonki I, Judd HL \& Chang RJ. The incidence of late-onset congenital adrenal hyperplasia due to 21hydroxylase deficiency among hirsute women. Journal of Clinical Endocrinology and Metabolism 198458 595-598.

9 Kuttenn F, Couillin P, Girard F, Billaud L, Vincens M, Boucekkine C, Thalabard J-C, Maudelonde T, Spritzer P, Mowszowicz I, Boue A \& Mauvais-Jarvis P. Late-onset adrenal hyperplasia in hirsutism. New England Journal of Medicine 1985313 224-231.

10 Azziz R \& Owerbach D. Molecular abnormalities of the 21hydroxylase gene in hyperandrogenic women with an exaggerated 17-hydroxyprogesterone response to short-term adrenal stimulation. American Journal of Obstetrics and Gynecology 1995 172 914-918.

11 Blanche H, Vexiau P, Clauin S, Le Gall I, Fiet J, Mornet E, Dausset J \& Bellanne-Chantelot C. Exhaustive screening of the 21-hydroxylase gene in a population of hyperandrogenic women. Human Genetics $199710156-60$.

12 Witchel SF, Lee PA, Suda-Hartman M \& Hoffman EP. Hyperandrogenism and manifesting heterozygotes for 21-hydroxylase deficiency. Biochemical and Molecular Medicine 199762 151158.

13 Knochenhauer ES, Cortez-Rudelli C, Cunningham RD, ConwayMyers BA, Dewailly D \& Azziz R. Carriers of 21-hydroxylase deficiency are not at increased risk for hyperandrogenism. Journal of Clinical Endocrinology and Metabolism 199782 479-485.

14 Dupont B, Smithwick EM, Oberfield SE \& Lee TD. Close genetic linkage between HLA and congenital adrenal hyperplasia (21hydroxylase deficiency). Lancet 1977 ii 1309-1312.

15 Speiser PW, New MI \& White PC. Molecular genetic analysis of nonclassic steroid 21-hydroxylase deficiency associated with HLAB14, DR1. New England Journal of Medicine 1988319 19-23.

16 Tillikainen A, Fischer G, Grubic Z, Gyodi E, Ivaskova E, Jungerman M, Kastelan A, Korinkova P, Martinovic I, Sociu-Foca N \& Vidan-Jeras B. Anthropological features of the East European region. In Genetic Diversity of HLA: Functional and Medical Implications, pp 307-313. Ed D Charron. Paris: EDK 1997.

17 Mittal KK, Mickey MR, Singal DP \& Terasaki PI. Serotyping for homotransplantation. XVIII. Refinement of microdroplet lymphocyte cytotoxicity test. Transplantation 19686 913-927.

18 Verduyn W, Doxiadis IIN, Anholts J, Drabbels JJM, Naipal A, D'Amaro J, Persijn GG, Giphart MJ \& Schreuder GMT for the Eurotransplant Centers. Biotylinated DRB sequence specific oligonucleotides: comparison to serologic HLA-DR typing of organ donors in Eurotransplant. Human Immunology 199337 59-67.

19 Olerup O \& Zetterquist H. HLA-DR typing by PCR amplification with sequence-specific primers (PCR-SSP) in $2 \mathrm{~h}$. Tissue Antigens $199239225-235$.

20 Miller SA, Dykes DD \& Polesky HF. A simple salting out procedure for extracting DNA from human nucleated cells. Nucleic Acid Research 1988161215.

21 Southern EM. Detection of specific sequences among DNA fragments separated by gel electrophoresis. Journal of Molecular Biology 197598 503-517.

22 White PC, Grossberger D, Onufer BJ, New MI, Dupont B \& Strominger JL. Two genes encoding steroid 21-hydroxylase are located near the genes encoding the fourth component of complement in man. Proceedings of the National Academy of Sciences of the USA 198582 1089-1093. 
23 Belt KT, Carroll MC \& Porter RR. The structural basis of the multiple forms of human complement component C4. Cell 1984 34 907-914.

24 White PC, Vitek A, Dupont B \& New MI. Characterization of frequent deletions causing steroid 21-hydroxylase deficiency. Proceedings of the National Academy of Sciences of the USA 1988 85 4436-4440.

25 Speiser P, Dupont J, Zhu D, Serrat J, Buegelesein M, Tusie-Luna MT, Lesser M, New MI \& White PC. Disease expression and molecular genotype in congenital adrenal hyperplasia due to 21 hydroxylase deficiency. Journal of Clinical Investigation 199290 584-595.

26 Wilson RC, Wei JQ, Cheng KC, Mercado AB \& New MI. Rapid deoxyribonucleic acid analysis by allele-specific PCR for detection of mutations in the steroid 21-hydroxylase gene. Journal of Clinical Endocrinology and Metabolism 199580 1635-1640.

27 Weddel A, Chun X \& Luthman H. A steroid 21-hydroxylase allele concomitantly carrying four disease-causing mutations is not uncommon in the Swedish population. Human Genetics 199493 204-206.

28 Tusie-Luna MT, Traktman P \& White PC. Determination of functional effects of mutations in the steroid 21-hydroxylase gene (CYP21) using recombinant vaccinia virus. Journal of Biological Chemistry 1990265 20916-20922.

29 Dondi E, Cuccia M, Keller E, Martinetti M, Larizza D \& Albert ED. Molecular analysis of CYP21B gene mutations carried on HLAB14 positive haplotypes. European Journal of Immunogenetics 1994 $21341-350$.

30 Azziz R, Rafi A, Smith BR, Bradley EL \& Zacur HA. On the origin of the elevated 17-hydroxyprogesterone levels after adrenal stimulation in hyperandrogenism. Journal of Clinical Endocrinology and Metabolism 199070 431-436.
31 Ostlere LS, Rumsby G, Holownia P, Jacobs HS, Rustin MHA \& Honour JW. Carrier status for steroid 21-hydroxylase deficiency is only one factor in the variable phenotype of acne. Clinical Endocrinology 199848 209-215.

32 Witchel SF \& Lee PA. Identification of heterozygotic carriers of 21hydroxylase deficiency: sensitivity of ACTH stimulation tests. American Journal of Medical Genetics 199876 337-342.

33 New MI, Lorenzen F, Lerner AJ, Kohn B, Oberfield SE, Pollack MS, Dupont B, Stoner E, Levy DJ, Pang S \& Levine LS. Genotyping steroid 21-hydroxylase deficiency: Hormonal reference data. Journal of Clinical Endocrinology and Metabolism 198357 320-326.

34 Gourmelen M, Gueux B, Pham Huu Trung MT, Fiet J, RauxDemay MC \& Girard F. Detection of heterozygous carriers for 21hydroxylase deficiency by plasma 21-deoxycortisol measurement. Acta Endocrinologica 1987116 507-512.

35 Peter M, Sippell WG, Lorenzen F, Willig RP, Westphal E \& GrosseWilde H. Improved test to identify heterozygotes for congenital adrenal hyperplasia without index case examination. Lancet 1990 335 1296-1299.

36 Vermesh M, Silva PA, Rosen GF, Vijod AG \& Lobo RA. Effects of androgen on adrenal steroidogenesis in normal women. Journal of Clinical Endocrinology and Metabolism 198866 128-130.

37 Liovic M. Prezelj J. Kocijancic A. Majdic G \& Komel R. CYP17 gene analysis in hyperandrogenised women with and without exaggerated 17-hydroxyprogesterone response to ovarian stimulation. Journal of Endocrinological Investigation 199720 189-193.

Received 25 November 1998

Accepted 27 April 1999 